\title{
Nota sobre leishmaniose canina no noroeste do Estado do Paraná, sul do Brasil ${ }^{\star}$
}

\section{Leishmaniasis in dogs in southern Brazil}

\author{
Maria Valdrinez Campana Lonardoni**, Ueslei Teodoro**, Sandra Mara Alessi Aristides Arraes**, Thaís Gomes \\ Verzignassi Silveira**, Dennis Armando Bertolini**, Edna A.Y. Ishikawa***, Jeffrey J. Shaw ${ }^{\star \star *}$
}

\begin{abstract}
LONARDONI, M.V.C. et al. Nota sobre leishmaniose canina no noroeste do Estado do Paraná, sul do Brasil. Rev. Saúde Pública, 27: 378-9, 1993. Em área endêmica de leishmaniose tegumentar americana no Município de Jussara, Estado do Paraná, Brasil, detectaram-se três cães domésticos infectados por Leishmania (Viannia) brasiliensis.
\end{abstract}

Descritores: Leishmaniose, epidemiologia. Leishmania, isolamento.

A leishmaniose tegumentar americana ocorre em ambientes florestais primitivos e tem sido classicamente descrita como uma zoonose ${ }^{6}$. Nesses ambientes, 0 ciclo do parasita processa-se sem a participação humana, caracterizando o foco silvestre, onde a manifestação da doença existe concomitantemente com a atividade humana ${ }^{4}$. Contudo, a parasitose humana vem sendo relatada em áreas que sofreram notáveis modificações ambientais $\mathrm{s}^{2,3,5}$.

NoEstado do Paraná, a leishmaniose cutânea vem sendo* notificada com frequiência, ocorrendo diversos casos entre mulheres e crianças $^{8,9}$. No Município de Jussara, Paraná, já foram assinalados inúmeros casos, inclusive entre membros de uma mesma família ${ }^{8}$.

A infecção de animais domésticos (cavalos, muares e cães) em áreas endêmicas ${ }^{1,3,6}$ sugere a participação desses animais na cadeia de transmissão de Leishmania nos ambientes domiciliar e peridomiciliar.

Alguns pacientes atendidos no laboratório da Universidade Estadual de Maringá relataram que seus cães também apresentavam úlceras de difícil cicatrização, lembrando a leishmaniose tegumentar. A investi-

* Apresentado no Encontro Científico da Universidade Estadual de Maringá, 4², Maringá, 1992.

* Departamento de Análises Clínicas da Universidade Estadual de Maringá - Maringá, PR - Brasil

*** Seção de Parasitologia doInstituto Evandro Chagas-Belém, PA - Brasil

Separatas/Reprints: M.V.C Lonardoni - Av. Colombo 3690 87020-900 - Maringá, PR - Brasil gação de três cães domésticos, pertencentes a moradores da fazenda Jussara, através de biópsia de lesões e esfregaçopor aposição, coradopelo métodode Giemsa, revelou a presença de formas amastigotas de Leishmania nos três animais (Tabela). O material de biópsia foi triturado em gral e inoculado nas patas traseiras de hamsters, nos quais posteriormente houve desenvolvimentode lesões, e destas isolou-se Leishmania em meio de cultura Blood Agar Base (BAB) ${ }^{10}$. As leishmânias isoladas dos três cães (MCAN/BR/91/1CS, MCAN/ $\mathrm{BR} / 91 / 2 \mathrm{CT}, \mathrm{MCAN} / \mathrm{BR} / 92 / 3 \mathrm{CAO}$ ) foram identificadas como serodema I de Leishmania (Viannia) braziliensis, com oemprego de método de identificação de anticorpos monoclonais ${ }^{7}$, no Instituto Evandro Chagas, Belém do Pará (Tabela).

Este é o primeiro relato de isolamento e identificação de Leishmania (Viannia) braziliensis em cães, no Estado do Paraná.

\section{Agradecimentos}

À Cia. Melhoramentos Norte do Paraná, de Cianorte, pelas facilidades que ofereceu para a realização desta investigação em terras de sua propriedade.

LONARDONI, M.V.C. et al. [Leishmaniasis in dogs in southern Brazil]. Rev. Saúde Pública, 27: 378-9, 1993. In an American cutaneous leishmaniasis endemic area in Jussara county, Paraná State, Brazil, three dogs were found to be infected by Leishmania (Viannia) braziliensis.

Keywords: Leishmaniasis, epidemiology.Leishmania, isolation. 
Tabela. Resultados da investigação de cāes domésticos com infecção por Leishmania (Viannia) braziliensis, na fazenda Jussara, Município de Jussara, Estado do Paraná, Sul do Brasil.

\begin{tabular}{lccc}
\hline \multicolumn{1}{c}{ Cão } & 1 & 2 & 3 \\
\hline Idade aproximada & 3 anos & 1,5 anos & 1,5 anos \\
Raça & indefinida & indefinida & pastor alemão \\
Número e local & 3 orelha & & \\
das lesões & 2 escroto & 3 escroto & 1 escroto \\
Evolução das lesões & 2 meses & 3 meses & 2 meses \\
Evolução das lesões em hamsters & 3 meses & 2 meses & 21 dias \\
Microscopia de material de lesão & positiva & positiva & positiva \\
Isolamento em cultura (BAB) & positivo & positivo & positivo \\
Parasito & L. $(V)$. & L. $(V)$. & L. (V.) \\
identificado (IEC) & braziliensis & braziliensis & braziliensis \\
Número de amostra & $1 \mathrm{CS}$ & $2 C T$ & 3 CAO
\end{tabular}

\section{Referências Bibllográficas}

1. AGUILAR, C.M. et al. Cutaneous leishmaniasis is frequent in equines from an endemic area in Rio de Janeiro, Brazil. Mem. Inst. Oswaldo Cruz, 81: 471-72, 1986.

2. DIAS,M. et al. Epidemiologia da leishmaniose tegumentar americana. I. Estudo de reservatórios em área endêmica no Estado de Minas Gerais. Rev.Inst.Med.Trop.S.Paulo, 19: 403-10, 1977.

3. FALQUETO, A. et al. Participação do cão no ciclo de transmis são de leishmaniose tegumentar no município de Viana, Estado do Espírito Santo, Brasil. Mem.Inst. Oswaldo Cruz, 81: 55-63, 1986

4. GOMES, A. de C. et al. Aspectos epidemiológicos da leishmaniose tegumentar americana. 8. Avaliação da atividade enzoótica de Leishmania (Viannia) braziliensis, em ambiente florestal e peridomiciliar, na região do Vale do Ribeira, Estado de São Paulo, Brasil. Rev.Inst. Med.Trop. S. Paulo, 32: 105-15, 1990

5. MAYRINK, W. et al. Epidemiology of dermal leishmaniasis in the Rio Doce Valley, state of Minas Gerais, Brazil. Ann. Trop. Med. Parasit., 73: 123-37, 1979.

6. FIRMEZ, C. et al. Canine american cutaneous leishmaniasis: a clinical and imunology study in dogs naturally infected with Leishmania (Viannia) braziliensis in an endemic area of Rio de Janeiro, Brazil. Amer. J. Trop. Med. Hyg., 38: 52 8, 1988.

7. SHAW, J.J. et al. A rapid and sensitive method for the identification of Leishmania with monoclonal antibodies using fluorescein labelled avidin. Trans. R. Soc. Trop. Med. Hyg., 83: 783-4, 1989.

8. TEODORO, U. et al. Da necessidade de se adotar e divulgar esquemas terapêuticos para tratamento de leishmaniose tegumentar no Paraná. Rev. Inst. Med. Trop. S. Paulo, 33: 199-204, 1991.

9. VERZIGNASSI, T.G. et al. Leishmaniose tegumentar americana: aspectos epidemiológicos no norte do Paraná, Brasil, In: Reunião da Sociedade Brasileira para o Progresso da Ciência, 40ãa, São Paulo, 1988. Anais. São Paulo, 1988. p. 884.

10. WALTON, B.C. et al. Observations on the in vitro cultivation of Leishmania braziliensis. J. Parasit., 63: 1118-9, 1977.

Recebido para publicação em 19.8 .92

Reapresentado em 9.8 .93

Aprovado para publicação em 23.8 .93 